\title{
Anti-Apoptotic Effect of Semelil on Testicular Germ Cells in Streptozotocin-Induced Chronic Diabetic Rats
}

\author{
Soheila Pourmasumi ${ }^{1}$, Mohammad-Mohsen T ${ }^{2}$, Mehrnaz Mehrabani ${ }^{3}$ and Maryam Anjomshoa ${ }^{4 *}$ \\ ${ }^{1}$ Research and Clinical Center for Infertility, Shahid Sadoughi University of Medical Sciences, Iran \\ ${ }^{2}$ Department of Anatomical Sciences, Rafsanjan University of Medical Sciences, Iran \\ ${ }^{3}$ Physiology Research Center, Kerman University of Medical Sciences, Iran \\ ${ }^{4}$ Department of Anatomical Sciences, Shahrekord University of Medical Sciences, Iran
}

Submission: July 4, 2017; Published: August 22, 2017

*Corresponding author: Maryam Anjomshoa, Department of Anatomical Sciences, Shahrekord University of Medical Sciences, Iran. Tel: +98-3813335652; Fax: +98-3813334911; E-mail: anjomshoa.m@gmail.com

Abstract

Background: It is well known that diabetes is associated with impairment of testicular function. The present study aimed to investigate the effect of Semilil, an herbal medicine with angiogenic action, on testicular germ cell apoptosis in streptozotocin (STZ)-induced chronic diabetic rats.

Methods: Adult Male sprague dawley rats were divided into 5 groups: (1) diabetic group, (2) Semilil-treated diabetic group, (3) insulintreated diabetic group, (4) Semilil plus insulin-treated diabetic group, and (5) control group. Semilil was administered intraperitoneally at the dose of $13 \mathrm{mg} / \mathrm{kg}$ for 49 days. Apoptosis in testicular germ cells was determined by terminal-deoxynucleotidyl-transferase-mediated dUTP nick end labeling (TUNEL) staining. Apoptosis indices in testicular germ cells of animals were computed using the stereologic method.

Results: Body and testis weights were significantly decreased in all of experimental groups, except in controls ( $\mathrm{P}<0.05$ each). The apoptosis index was significantly increased in the diabetic dams when compared to control and insulin treated diabetic animals $(\mathrm{P}<0.01$ and $\mathrm{P}<0.01$, respectively). Although, the apoptosis index was markedly increased in Semilil-treated diabetic group compared to insulin treated diabetic group animals and controls $(\mathrm{P}<0.01 \& \mathrm{P}<0.001$, respectively), there was a significant decrease in the apoptosis index of germ cells in the Semilil-treated diabetic group with respect to the diabetic group $(\mathrm{P}<0.01)$.

Conclusion: These results suggest that intraperitoneal administration of Semili for seven weeks has a potentially beneficial role in reducing apoptosis in testicular germ cell in chronic diabetic adult rats, probably due to improve the angiogenesis.

Keywords: Apoptosis; Spermatogenesis; Diabetes

\section{Introduction}

Diabetes is associated with human reproductive dysfunction in both males and females [1-7]. The increasing incidence of diabetes diagnosed at reproductive age is an issue showing the importance of research on fertility in this group [1-3,6-7]. Several lines of studies demonstrate that diabetes affects male reproductive function at multiple levels due to its effects on the endocrine control of spermatogenesis, spermatogenesis itself or by impairing penile erection and ejaculation [1-8].

In previous studies, histopathological and histomorphometric alterations in seminiferous tubules have been reported in streptozotocin-induced diabetic animals [9-14]. In a study Guneli et al. [15] and coworkers showed a reduction in seminiferous tubule diameter, increased thickening of the basement membrane in seminiferous tubules and degenerated germ cells in diabetic rats. They also found that TUNEL-positive cells were significantly more numerous in diabetic rats than in controls. Moreover, Sainio-Pollanen et al. [16] and Cai et al. [11] revealed that diabetes increased apoptosis in testicular germ cells in mice.

The exact mechanism by which diabetes leads to male reproductive system dysfunction is not completely understood $[1-3,17]$. While, some human studies revealed that psychological issues and blood flow disruption are the main causes $[3,8,18]$. Numerous studies on rodents also suggest mechanisms including altered hormonal profiles, oxidative stress, DNA damage to sperm, and abnormal progression through spermatogenesis $[3,5,10,15,18-21]$. Diabetes also adversely affects seminiferous 


\section{Global Journal of Reproductive Medicine}

epithelium including increased basement membrane thickness, degeneration and apoptosis of germ cells [5,9-13,16,21,22].

Semelil (ANGIPARS ${ }^{\mathrm{TM}}$ ), an extract of Melilotus officinalis (Yellow Sweet Clover), is a new herbal drug for diabetic foot ulcers management that has been formulated by Iranian scientists in recent years and according to the results of recent studies, this drug is effective and safe. Previous studies have reported a beneficial effects of Melilotus officinalis extract in microcirculation improvement in leg chronic venous insufficiency and hydrocortisone-like anti-inflammatory effects. ANGIPARS ${ }^{\mathrm{TM}}$ also contains compounds such as 7-Hydroxycoumarin and flavonoids which have potent antioxidant effects [23-26]. Since a possible mechanism for this drug is angiogenesis and an increase in tissue blood flow and oxygenation; in this study, we assumed that the Semelil (ANGIPARS ${ }^{\mathrm{TM}}$ ) has a protective action on chronic diabetes induced apoptosis in germinal cells of seminifrous tubules as a result of improve in blood flow.

\section{Material and Methods}

\section{Animals}

Study Design and Experimental Groups: All procedures involving animals were in accordance with the Guide for the Care and Use of Laboratory Animals of Mashhad University of Medical Sciences, Mashhad, Iran. Sixty adult Sprague Dawley male rats (300-350g body weight, 6-8 weeks old) were purchased from Mashhad University of Medical Sciences Experimental Animal House (Mashhad, Iran). Animals were housed in individual cages at $22 \pm 2{ }^{\circ} \mathrm{C}$ with free access to pellet food and water and on a $12 \mathrm{~h}$ light/dark cycle. They were fed a regular rat chow.

Diabetes was induced by intraperitoneal (i.p.) injection of $65 \mathrm{mg} / \mathrm{kg}$ streptozotocin STZ, (Sigma, St. Louis, MO, USA) in 0.1M citrate buffer ( $\mathrm{pH}$ 4.5). Two days after STZ injection, development of diabetes was confirmed by measuring glucose level in fasting blood samples taken from tail vein using Accu-Chek glucometer (Roche, Germany). Rats with blood glucose concentrations of $300 \mathrm{mg} / \mathrm{dl}$ or higher were considered diabetic and included in the study.

The rats were randomly divided into five groups $(n=12$ each): (1) diabetic group, (2) Semilil- treated diabetic group, (3) insulin-treated diabetic group, (4) Semilil plus insulin- treated group, and (5) control group. Animals were kept diabetic for 56 days and treated the next 49 days with Semilil (13mg/kg; i.p.). Semilil (ANGIPARS ${ }^{\text {тM }}$ ) was freshly diluted in sterile saline $(0.9 \%$ sodium chloride) at 1:10. Animal weights were measured before and at the end of the treatment period using a digital scale.

\section{Tissue Sampling}

The treatment continued for 49 consecutive days, and then the animals were anesthetized with thiopental $(40 \mathrm{mg} / \mathrm{kg}$, ip). The thorax of each animal was opened with surgical incision on the sternum and the perfusion was done from left ventricle and right atrium. A rinsing solution was perfused before the fixation solution (Bouin`s fluid). Due to the narrow testicular artery branches from the abdominal aorta near the renal artery, it is probably constricted and occluded during the perfusion process. Perfusion with rinsing solution helped overcome this problem. To make rinsing solution, 9.0 $\mathrm{gaCl}, 25 \mathrm{~g}$ Polyvinyl Pyrrolidone, $0.25 \mathrm{~g}$ Heparin, and 5.0g Procain-HCL were dissolved in one liter of water by thorough stirring.

The $\mathrm{pH}$ was adjusted to 7.35 with $1 \mathrm{~N} \mathrm{NaOH}$ and twice filtered through Millipore filters of $3.0 \mu \mathrm{m}$ or less pore size. The perfusion of both solutions was performed by using a scalp vein attached to a 50cc syringe. Testes were immediately removed taking care to handle specimens gently to minimize trauma to the tissues prior to placement of each tissue into fixative solution. The tunica albuginea was shallowly pierced at each pole 5 times with a 21-gauge needle to aid in the penetration of the fixative solution. Fixation time was limited to 24 hours and tissues were transferred using 70\% ethyl alcohol.

Alcohol was changed 3 times daily for 2 days before transferring the specimens to a saturated solution of $70 \%$ ethyl alcohol and lithium carbonate to neutralize the picric acid in Bouin's fluid. The ethyl alcohol-lithium carbonate solution was changed 3 or more times until the yellow color of Bouin's fluid was almost completely depleted from the tissue. Tissues were stored in $70 \%$ ethyl alcohol until they were processed $[27,28]$. The fixed tissues were dehydrated through a graded series of ethanol and embedded in paraffin according to standard procedures. Paraffin sections were placed on slides coated with poly-L-lysine and stored at room temperature until further processing. The $7 \mu \mathrm{m}$ thick paraffin sections were used for Terminal deoxynucleotidylransferase dUTP nick end labeling (TUNEL) staining methods. The occurrence of apoptotic cell death in the testicular tissue was examined [22].

\section{In Situ Germ Cell Apoptosis Detection}

In situ cell death detection kit was purchased from Roche (Germany). Apoptosis process in testicular germ cells was examined following the manufacturer's protocol. Seven micrometer thick sections were deparaffinized, rehydrated, washed in Phosphate Buffered Saline (PBS) and incubated with proteinase $\mathrm{K}(1 \mathrm{mg} / \mathrm{ml})$ for $15-30 \mathrm{~min}$ at $18-24{ }^{\circ} \mathrm{C}$. Peroxidase activity was quenched with the addition of $3 \% \mathrm{H}_{2} \mathrm{O}_{2}$ in absolute methanol. Sections were washed with PBS and incubated with the TUNEL reaction mixture of terminal deoxynucleotidyl transferase plus the nucleotide mixture in reaction buffer in a moist chamber for $60 \mathrm{~min}$ at $37 \mathrm{C}$ in the dark.

Sections were washed with PBS then incubated with converter-AP containing antifluorescein antibody (Fab fragment from sheep) conjugated with Alkaline Phosphates (ALP) in a humidified chamber for $30 \mathrm{~min}$ at $37^{\circ} \mathrm{C}$. PBS rinsing and incubation with substrate solution that contained $7 \mathrm{mg}$ diaminobenzidine (DAB) (Sigma) and $3 \mathrm{ml} \mathrm{H} 2 \mathrm{O} 2$ in $10 \mathrm{ml}$ of $50 \mathrm{mM}$ Tris- $\mathrm{HCl}, \mathrm{pH} 7.4$ for $10 \mathrm{~min}$ at $15-25{ }^{\circ} \mathrm{C}$ in the dark followed. PBS rinsing and counterstaining with Hematoxylin at room temperature for $1 \mathrm{~min}$ was followed. Negative control 


\section{Global Journal of Reproductive Medicine}

sections were processed with label solution (without terminal transferase) and positive control sections were incubated with micrococcal nuclease or recombinant DNase 1 to induce DNA strand breaks, prior to labeling.

The stained samples of testis were semi-quantitatively analyzed, so that the number of positive spermatogonia cells per 50 seminiferous tubules was counted in 50 randomly chosen fields in four testis cross sections per animal, and data were corrected for seminiferous tubule diameter. This value was expressed as an index which evaluates the changes in apoptotic activity. The index was calculated using the equation:

Where $\mathrm{n}(\mathrm{tub}+)$ =percentage of positive tubules; $\mathrm{n}$ (cell+) $=$ number of positive spermatogonia per tubule; $\mathrm{n}$ (total) =total number of tubules; $d=$ seminiferous tubule diameter (mm) [23].

\section{Data Analysis}

Differences between groups were measured using an Analysis of Variance (one way ANOVA). Tukey-Kramer test was employed afterward, where appropriate. All data are presented as mean \pm S.D. Differences were considered significant at $\mathrm{P}<0.05$.

Results

Table 1: Blood glucose concentrations, body and testis weights of animals in different studied groups. The data presented as mean \pm S.D. (n=12).

\begin{tabular}{|c|c|c|c|c|c|}
\hline Group & $\begin{array}{l}\text { Blood Glucose Level } \\
\text { (Mg/Dl) }\end{array}$ & $\begin{array}{l}\text { Animal Weight } \\
\text { Before Starting the } \\
\text { Experiments(G) }\end{array}$ & $\begin{array}{l}\text { Animal Weight } \\
\text { at the End of the } \\
\text { Experiments }\end{array}$ & Testis Weight & $\begin{array}{c}\text { Testis Weight/Body } \\
\text { Weight Ratio }\end{array}$ \\
\hline Control & $109.1 \pm 6.6$ & $345.2 \pm 7.3$ & $294.2 \pm 6.6$ & $1.28 \pm 0.07$ & $3.78 \pm 0.53$ \\
\hline Diabetic & $422.9 \pm 12.6^{* *}$ & $342.14 \pm 7.4$ & $238.2 \pm 7.2^{*}$ & $0.72 \pm 0.07^{* *}$ & $3.02 \pm 0.82$ \\
\hline $\begin{array}{l}\text { Semilil Treated- } \\
\text { Diabetic }\end{array}$ & $404.2 \pm 17.4^{* *}$ & $350.1 \pm 9.3$ & $287.1 \pm 11.1^{*}$ & $1.08 \pm 0.09^{* *}$ & $3.76 \pm 0.86^{* * *}$ \\
\hline $\begin{array}{c}\text { insulin-treated } \\
\text { diabetic }\end{array}$ & $128.8 \pm 8.1$ & $338.8 \pm 8.6$ & $281 \pm 9.7^{*}$ & $0.94 \pm 0.09^{* *}$ & $3.35 \pm 0.82^{* * *}$ \\
\hline $\begin{array}{l}\text { Semilil plus insulin- } \\
\text { treated diabetic }\end{array}$ & $124.3 \pm 5.3$ & $345.2 \pm 7.3$ & $294.2 \pm 6.57^{*}$ & $1.11 \pm 0.08^{* *}$ & $3.78 \pm 0.053^{* * *}$ \\
\hline
\end{tabular}

*Significant differences compared to before starting the experiment $(P<0.05)$.

**Significant differences compared to control $(P<0.05)$.

***Significant differences compared to diabetic group $(P<0.05)$

Detailed data for blood glucose concentrations, body and testis weights of animals before and at the end of the experiments in different groups are presented in Table 1 As shown, blood glucose levels in diabetic and Semilil-treated diabetic animals were significantly increased when compared to controls $(\mathrm{P}<0.001$ each). Moreover, Body and testis weights were significantly decreased in all of experimental groups, except in controls $(\mathrm{P}<0.05$ each). Testis weight/ Body weight ratio also was strikingly increased in Semilil, Insulin, and Semilil plus Insulintreated animals compared to untreated diabetic group $(\mathrm{P}<0.05$ each). In our study, diabetic rats exhibited some symptoms commonly associated with diabetes (i.e. polyuria, polydipsia and diarrhea).

\section{Evaluation of TUNEL Staining}

Figure 1 represents the presence of TUNEL-positive cells in seminiferous tubules of rats in different groups. While, the number of TUNEL-positive cells in the control group was negligible (Figure 1); these cells were observed in all of the spermatogenic cell series in the seminiferous tubules of other experimental animals (Figure 1). Analyzing the apoptosis index, our results showed that the apoptosis index was significantly increased in the diabetic dams when compared to control, Semilil-, Semilil plus insulin- and insulin-treated diabetic groups $(\mathrm{P}<0.001, \mathrm{P}<0.01$ and $\mathrm{P}<0.01$, respectively; fig. 2). Although the apoptosis index was markedly increased in Semilil-treated diabetic group compared to controls $(\mathrm{P}<0.01$; Figure 2), there was a significant decrease in the apoptosis index in the Semililtreated diabetic group with respect to the diabetic group $(\mathrm{P}<0.001$; Figure 2). Significant changes were determined in apoptosis index of the Semilil-treated diabetic group compared to the insulin treated group animals $(\mathrm{P}<0.01$; $)$.

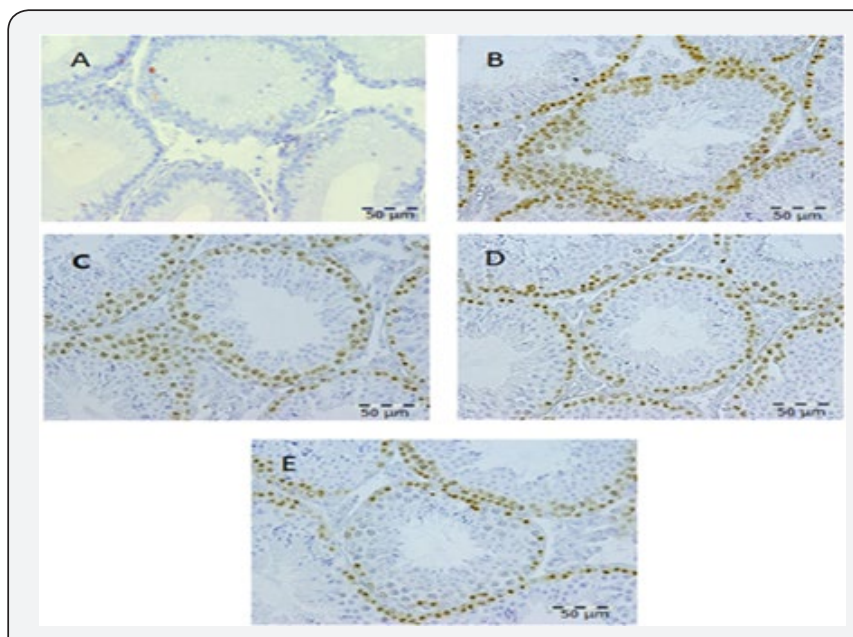

Figure 1: Representative photomicrographs illustrating TUNEL positive cells as an index of apoptosis in seminiferous tubules in control (A) diabetic (B) Semilil-treated diabetic (C) insulintreated diabetic $(D)$ Semilil plus insulin (E) group animals. Scale bar $=50 \mu \mathrm{m}$ 


\section{Global Journal of Reproductive Medicine}

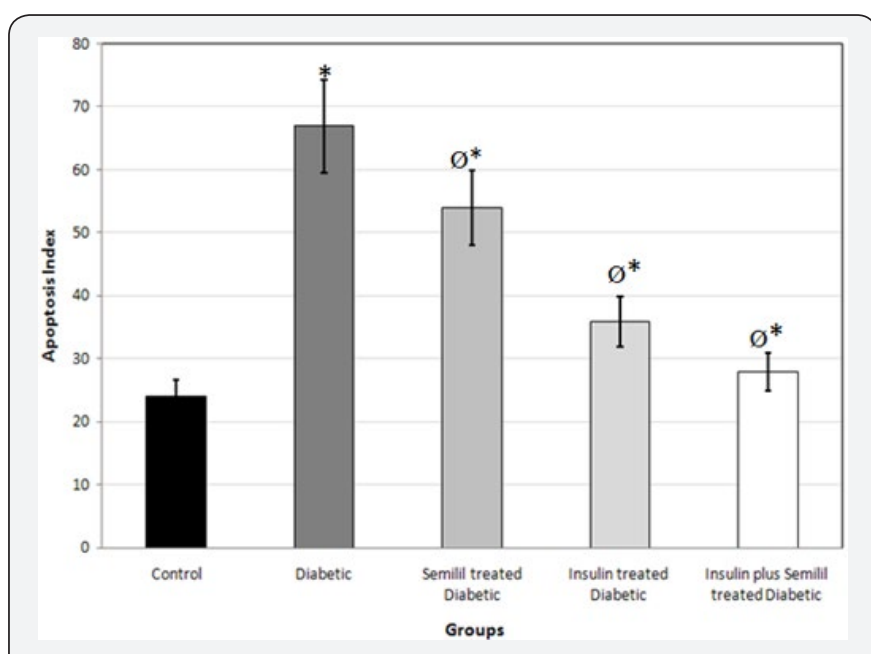

Figure 2: Apoptosis index of germ cells in seminifrous tubules in different studied groups. The data presented as mean \pm S.D. $(n=12)$.

*Significant differences compared to control $(P<0.05)$

$\varnothing$ Significant differences compared to diabetic group $(P<0.01)$.

\section{Discussion}

In this investigation, in situ detection of DNA fragments using the TUNEL assay was undertaken to investigate active germ cell apoptosis induced by diabetes $[11,15]$. This method is commonly used in the measurement of apoptosis in several organs other than the testis [29-31]. Our study demonstrated that STZ-induced chronic diabetes in male rats caused increase in apoptosis index of testicular germ cells, and Similil treatment has beneficial effect on preventing the germinal cell apoptosis and the loss of spermatogenic cell series; probably by providing a better blood supply in seminiferous tubules. Besides, the apoptosis indices in the germinal epithelium of testis were significantly increased in the diabetic animals, an indication of apoptosis induced by diabetes in our adult male rats. However, the germ cell apoptosis index was reduced after Semilil treatment in diabetic dams.

The present study results are consistent with those of previous studies that report diabetes induces apoptosis in seminiferous tubules $[11,12,15,16,32]$. Diabetes induced apoptosis during spermatogenesis resulting in testicular dysfunction. So, apoptosis plays a crucial role in the pathogenesis of testicular dysfunction in diabetic males $[11,12,15]$. Although, there are challenges about the mechanisms by which diabetes causes testicular germ cell apoptosis. Some researchers believe that diabetes induces germinal cell apoptosis and alters spermatogenes in result of drastically reduction in testosterone level [16,32]. Koh and coworkers focused on the pathways by which diabetes induces apoptosis in rat testes. They found that streptozotocin-induced diabetes increased the number of apoptotic cell due to phosphorylation of Jun $\mathrm{N}$-terminal kinases (JNKs) and activation of box [12].

Numerous studies reported that diabetes markedly affects the sexual behavior and reproductive functions, which can lead to reduced fertility $[3,5,6,17,19,21]$.
Human and animals studies have been shown that diabetes induces male reproductive structural and behavioral alterations by causing apoptotic cell death, atrophy of the seminiferous tubules, decreased tubule diameters and reduction of spermatogenetic cell series $[1,2,5,9,10,13,15,22]$. Seminiferous tubule atrophy and the decrease in germinal cells were morphological indicators of spermatogenesis failure $[5,9,10,13,15,22]$. In humans also diabetes is associated with decrease of plasma levels of testosterone and gonadotrophins, and abnormal morphology of sperm $[17,33]$. Previous studies have shown that diabetes disturbs the proliferation and differentiation of Leydig cells, and changes the pituitarytesticular axis [7]. A reduction in testicular weight and atrophy of the seminiferous tubules were also observed in diabetic rats $[5,11]$. In this study, we assumed that the lack of optimal blood supply to testis in diabetic animals may cause an increase in apoptosis in germ cells in seminiferous tubules.

Semelil (ANGIPARS ${ }^{\mathrm{TM}}$ ) is a novel herbal drug containing Melilotus officinalis extract that recently approved for treatment of chronic wounds, particularly diabetic foot ulcers [23-26]. In the recent investigations, ANGIPARS ${ }^{\mathrm{TM}}$ showed an evident angiogenic effect. So, this drug could significantly accelerate wound healing [23-26]. It was expected that ANGIPARS ${ }^{\mathrm{T}}$ improve diabetic induced apoptosis in germinal cells in testis.

Testicular germ cell apoptosis is consistent with morphological analysis in the seminiferous tubules $[15,34]$. In the present study, TUNEL-positive cells showed the typical morphological features of apoptosis including chromatin condensation, cytoplasmic budding and apoptotic bodies. The apoptosis index in the testicular germinal epithelium was significantly increased in diabetic male animals, indicating that germinal cell apoptosis was induced by diabetes in rat testes. There were markedly fewer TUNEL-positive cells in the diabetic rats treated with Semilil.

On the other hand, it has previously been shown that diabetes increases oxidative stress in the diabetic male testis [35-40]. Under an elevated oxidative stress status, reactive oxygen species cause cellular injury via several mechanisms including lipid peroxidation and oxidative damage of proteins and DNA [35, 41-43]. Oxidative stress is recognized as a strong mediator of apoptosis [41-43]. Mitochondria have a key role in the apoptotic process [42-45]. The mitochondrial dysfunction induced by oxidative stress can lead to the release of cytochrome c and then caspase activation, which results in apoptotic cell death $[42-43,46]$.

In the present study, we demonstrated that Semilil prevents diabetes- induced germinal cell loss in the diabetic male rat. These findings indicate that the germinal cell-protective effects of Semilil may reflect its role as a free radical scavenger, an antioxidant, an antiapoptotic or an anti-inflammatory agent. The thickness of the seminiferous tubule basement membranes plays an important role in spermatogenesis. Several studies 


\section{Global Journal of Reproductive Medicine}

have revealed that diabetes increases the thickening of the seminiferous tubule basement membranes [47,48], and this thickness is accompanied by a decreased rate of sperm production and overall reduction in the size of seminiferous tubules. In the present study, light-microscopic examination revealed that thickness of the seminiferous tubule basement membranes increased in diabetic rat testes, but Semilil reduced this increase in thickness.

In conclusion, Semilil improves the testicular damage in chronic diabetic male rats. To our knowledge, this is the first report indicating that Semilil improved diabetes induced testicular dysfunction in diabetic rats. Semilil can contribute to a balanced oxidant-antioxidant status and provide a useful therapeutic option to reduce the associated testes injury in patients with diabetes mellitus.

\section{Conclusion}

These results suggest that intraperitoneal administration of Semili for seven weeks has a potentially beneficial role in reducing apoptosis in testicular germ cell in chronic diabetic adult rats, probably due to improve the angiogenesis.

\section{Acknowledgment}

This study was financially supported by the grant from the vice chancellors for research, Rafsanjan and Mashhad University of Medical Sciences, Iran. The authors gratefully acknowledge Dr. Javad Hami for his helpful comments.

\section{Funding}

The study was funded by Medical Education for Equitable Services to All Ugandans Consortium (MESAU).

\section{References}

1. Agbaje IM, Rogers DA, McVicar CM, McClure N, Atkinson AB, et al (2007) Insulin dependent diabetes mellitus: implications for male reproductive function. Hum Reprod 22(7): 1871-1877.

2. Sexton WJ, Jarow JP (1997) Effect of diabetes mellitus upon male reproductive function. Urology 49(4): 508-513.

3. Fairburn CG, McCulloch DK, Wu FC ( 1982) The effects of diabetes on male sexual function. Clin Endocrinol Metab 11(3): 749-767.

4. Kim NN, Stankovic M, Cushman TT, Goldstein I, Munarriz R, et al. (2006) Streptozotocin-induced diabetes in the rat is associated with changes in vaginal hemodynamics, morphology and biochemical markers BMC Physiol 6:4.

5. Scarano WR, Messias AG, Oliva SU, Klinefelter GR, Kempinas WG (2006) Sexual behaviour, sperm quantity and quality after short-term streptozotocin-induced hyperglycaemia in rats. Int J Androl 29(4): 482-488.

6. Schiavi RC, Stimmel BB, Mandeli J, Rayfield EJ (1993) Diabetes mellitus and male sexual function: a controlled study. Diabetologia 36(8): 745751.

7. Steger RW, Rabe MB (1997) The effect of diabetes mellitus on endocrine and reproductive function. Proc Soc Exp Biol Med 214(1): 1-11.

8. Musicki B, Ross AE, Champion HC, Burnett AL, Bivalacqua TJ (2009) Posttranslational modification of constitutive nitric oxide synthase in the penis. J Androl 30(4): 352-362.
9. Altay B, Cetinkalp S, Doganavsargil B, Hekimgil M, Semerci B (2003) Streptozotocin-induced diabetic effects on spermatogenesis with proliferative cell nuclear antigen immunostaining of adult rat testis. Fertility and Sterility 80 Suppl 2: 828-831.

10. Anderson JE, Thliveris JA (1986) Testicular histology in streptozotocininduced diabetes. Anat Rec 214(4): 378-382.

11. Cai L, Chen S, Evans T, Deng DX, Mukherjee K, et al. (2000) Apoptotic germ-cell death and testicular damage in experimental diabetes: prevention by endothelin antagonism. Urol Res 28(5): 342-347.

12. Koh PO (2007) Streptozotocin-induced diabetes increases apoptosis through JNK phosphorylation and Bax activation in rat testes. J Vet Med Sci 69(9): 969-971.

13. Rossi GL, Aeschlimann M (1982) Morphometric studies of pituitary glands and testes in rats with streptozotocin-induced diabetes. Andrologia 14(6): 532-542.

14. Sanguinetti RE, Ogawa K, Kurohmaru M, Hayashi Y (1995) Ultrastructural changes in mouse Leydig cells after streptozotocin administration. Exp Anim 44(1): 71-73.

15. Guneli E, Tugyan K, Ozturk H, Gumustekin M, Cilaker S, et al. (2008) Effect of melatonin on testicular damage in streptozotocin-induced diabetes rats. Eur Surg Resb 40(4): 354-360.

16. Sainio-Pollanen S, Henriksen K, Parvinen M, Simell O, Pollanen P (1997) Stage-specific degeneration of germ cells in the seminiferous tubules of non-obese diabetic mice. Int J Androl 20(4): 243-253.

17. Dinulovic D, Radonjic G (1990) Diabetes mellitus/male infertility. Arch Androl 25(3): 277-293.

18. Bivalacqua TJ, Champion HC, Usta MF, Cellek S, Chitaley K, et al. (2004) RhoA/Rho-kinase suppresses endothelial nitric oxide synthase in the penis: a mechanism for diabetes-associated erectile dysfunction. Proc Natl Acad Sci U S A 101(24): 9121-9126.

19. Hassan AA, Hassouna MM, Taketo T, Gagnon C, Elhilali MM (1993). The effect of diabetes on sexual behavior and reproductive tract function in male rats. J Urol 149(1): 148-154.

20. Soudamani S, Yuvaraj S, Rengarajan S, Sivakumar R, Malini T, et al. ( 2006) Effects of streptozotocin-diabetes and insulin replacement on androgen and estrogen receptor concentrations in the epididymis of Wistar rats. Journal of Endocrinology and Reproduction 10(1): 59-61.

21. Steger RW (1990) Testosterone replacement fails to reverse the adverse effects of streptozotocin-induced diabetes on sexual behavior in the male rat. Pharmacol Biochem Behav 35(3): 577-582.

22. Arikawe AP, Daramola AO, Odofin AO, Obika LF (2006) Alloxan-induced and insulin-resistant diabetes mellitus affect semen parameters and impair spermatogenesis in male rats. Afr J Reprod Health 10(3): 106113.

23. Larijani B, Heshmat R, Bahrami A, Delshad H, Ranjbar Omrani G, et al. Effects of intravenous Semelil (ANGIPARSTM) on diabetic foot ulcers healing: A multicenter clinical trial DARU Journal of Pharmaceutical Sciences 16(Suppl. 1): 35-40.

24. Shamimi Nouri K, Heshmat R, Karimian R, Nasli E, Larijani B, et al. (2008) Intravenous Semelil (ANGIPARS ${ }^{\mathrm{TM}}$ ) as a novel therapy for pressure Ulcers: A randomized clinical trial. DARU Journal of Pharmaceutical Sciences 16(Suppl 1): 49-53.

25. Shamimi Nouri K, Karimian R, Nasli E, Kamali K, Chaman R et al. (2008) Topical application of Semelil (ANGIPARS ${ }^{\mathrm{TM}}$ ) in treatment of pressure ulcers: A randomized clinical trial. DARU Journal of Pharmaceutical Sciences 16(1): 54-57.

26. Larijani B, Hasani Ranjbar S (2008) Overview of diabetic foot; novel treatments in diabetic foot ulcer. DARU Journal of Pharmaceutical Sciences 16(suppl.1): 1-6. 


\section{Global Journal of Reproductive Medicine}

27. Forssmann WG, Ito S, Weihe E, Aoki A, Dym M et al. (1977) An improved perfusion fixation method for the testis. Anat Rec 188(3): 307-314.

28. Latendresse JR, Warbrittion AR, Jonassen H, Creasy DM (2002) Fixation of testes and eyes using a modified Davidson's fluid: comparison with Bouin's fluid and conventional Davidson's fluid. Toxicol Pathol 30(4) 524-533.

29. Brazdil J, Lukas Z, Hermanova M, Pazourkova M, Ruzicka M, et al (2003) [Apoptosis and expression of bcl-2 protein in invasive ductal adenocarcinoma of the pancreas]. Cesk Patol 39(4): 168-173.

30. Pulkkanen KJ, Laukkanen MO, Naarala J, Yla-Herttuala S (2000) Falsepositive apoptosis signal in mouse kidney and liver detected with TUNEL assay. Apoptosis 5(4): 329-333.

31. Kasahara I, Saitoh K, Nakamura K (2000) Apoptosis in acute hepatic failure: histopathological study of human liver tissue using the tune method and immunohistochemistry. J Med Dent Sci 47(3): 167-175.

32. Sinha Hikim AP, Lue Y, Diaz-Romero M, Yen PH, Wang C et al. (2003) Deciphering the pathways of germ cell apoptosis in the testis. J Steroid Biochem Mol Biol 85(2-5): 175-182.

33. Mallick C, Mandal S, Barik B, Bhattacharya A, Ghosh D (2007) Protection of testicular dysfunctions by MTEC, a formulated herbal drug, in streptozotocin induced diabetic rat. Biol Pharm Bull 30(1): 84-90.

34. Russell LD, Alger LE, Nequin LG (1987) Hormonal control of pubertal spermatogenesis. Endocrinology 120(4): 1615-1632.

35. Sasaki S, Inoguchi T (2012) The role of oxidative stress in the pathogenesis of diabetic vascular complications. Diabetes Metab J 36(4): 255-261.

36. Yamagishi S (2009) Advanced glycation end products and receptoroxidative stress system in diabetic vascular complications. Ther Apher Dial 13(6): 534-539.

37. Inoguchi T, Takayanagi $\mathrm{R}$ (2008) [Role of oxidative stress in diabetic vascular complications]. Fukuoka Igaku Zasshi 99(3): 47-55.

38. Komosinska-Vassev K, Olczyk K, Olczyk P, Winsz-Szczotka (2005) Effects of metabolic control and vascular complications on indices of oxidative stress in type 2 diabetic patients. Diabetes Res Clin Pract 68(3): 207-216

39. Son SM, Whalin MK, Harrison DG, Taylor WR, Griendling KK (2004) Oxidative stress and diabetic vascular complications. Curr Diab Rep 4(4): 247-252.

40. Giugliano D, Ceriello A, Paolisso G (1996) Oxidative stress and diabetic vascular complications. Diabetes Care19(3): 257-267.

41. Buttke TM, Sandstrom PA (1994) Oxidative stress as a mediator of apoptosis. Immunol Today 15(1): 7-10.

42. Sinha K, Das J, Pal PB, Sil PC (2013) Oxidative stress: the mitochondriadependent and mitochondria-independent pathways of apoptosis. Arch Toxicol 87(7): 1157-1180.

43. Jiang J, Zuo Y, Gu Z (2013) Rapamycin protects the mitochondria against oxidative stress and apoptosis in a rat model of Parkinson's disease. Int J Mol Med 31(4): 825-832.

44. Yuzefovych LV, Musiyenko SI, Wilson GL, Rachek LI (2013) Mitochondrial DNA damage and dysfunction, and oxidative stress are associated with endoplasmic reticulum stress, protein degradation and apoptosis in high fat diet-induced insulin resistance mice. PLoS One 8(1): e54059.

45. Chin MH, Qian WJ, Wang H, Petyuk VA, Bloom JS, et al. (2008) Mitochondrial dysfunction, oxidative stress, and apoptosis revealed by proteomic and transcriptomic analyses of the striata in two mouse models of Parkinson's disease. J Proteome Res 7(2): 666-677.

46. Lin TK, Cheng CH, Chen SD, Liou CW, Huang CR, etal. (2012) Mitochondrial Dysfunction and Oxidative Stress Promote Apoptotic Cell Death in the Striatum via Cytochrome c/Caspase-3 Signaling Cascade Following Chronic Rotenone Intoxication in Rats. Int J Mol Sci 13(7): 8722-8739.

47. Abrahamson DR (1986) Recent studies on the structure and pathology of basement membranes. J Pathol 149(4): 257-278.

48. Rohrbach DH, Martin GR (1982) Structure of basement membrane in normal and diabetic tissue. Ann N Y Acad Sci 401:203-211.

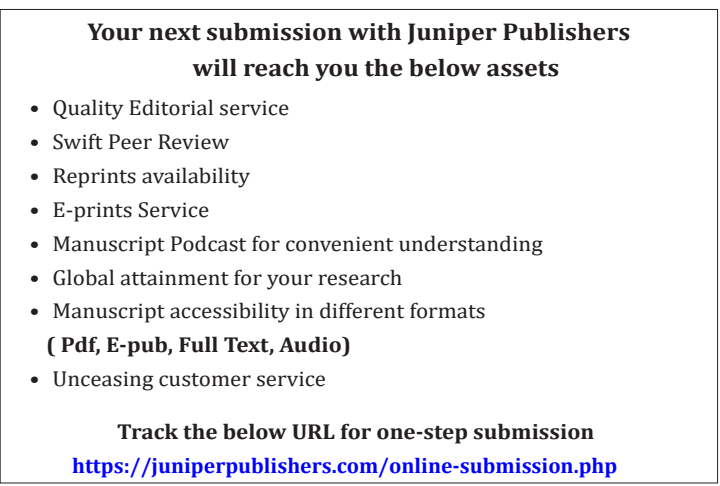

